\title{
Performance Enhancement of a Graphene-Zinc Phosphide Solar Cell Using the Electric Field-Effect
}

\author{
Oscar Vazquez-Mena, ${ }^{*}, \dagger, \ddagger$ Jeffrey P. Bosco,,${ }^{\S, \|}$ O. Ergen, ${ }^{\dagger, \dagger}$ Haider I. Rasool, ${ }^{\dagger, \dagger}$ Aidin Fathalizadeh, ${ }^{\dagger, \dagger}$ \\ Mahmut Tosun, ${ }^{\ddagger, \perp}$ Michael Crommie, ${ }^{\dagger, \ddagger, \#}$ Ali Javey, ${ }^{\dagger, \perp}$ Harry A. Atwater, ${ }^{\S, \|}$ and Alex Zettl ${ }^{*}, \dagger, \ddagger, \#$ \\ ${ }^{\dagger}$ Department of Physics, University of California, Berkeley, California 94720, United States \\ ${ }^{\ddagger}$ Material Sciences Division, Lawrence Berkeley National Laboratory, Berkeley, California 94720, United States \\ ${ }^{\S}$ Department of Applied Physics and "Department of Chemical Engineering, California Institute of Technology, Pasadena, California \\ 91125, United States \\ ${ }^{\perp}$ Electrical Engineering and Computer Sciences, University of California, Berkeley, California 94720, United States \\ ${ }^{\#}$ Kavli Energy Nanosciences Institute at the University of California, Berkeley, and the Lawrence Berkeley National Laboratory, \\ Berkeley, California 94720, United States
}

\section{Supporting Information}

ABSTRACT: The optical transparency and high electron mobility of graphene make it an attractive material for photovoltaics. We present a field-effect solar cell using graphene to form a tunable junction barrier with an Earth-abundant and low cost zinc phosphide $\left(\mathrm{Zn}_{3} \mathrm{P}_{2}\right)$ thin-film light absorber. Adding a semitransparent top electrostatic gate allows for tuning of the graphene Fermi level and hence the energy barrier at the graphene- $\mathrm{Zn}_{3} \mathrm{P}_{2}$ junction, going from an ohmic contact at negative gate voltages to a rectifying barrier at positive gate voltages. We perform current and capacitance measurements at different gate voltages in order to demonstrate the control of the energy barrier and depletion width in the zinc phosphide. Our photovoltaic measurements show that the efficiency conversion is increased 2-fold when we increase the gate voltage and the junction barrier to maximize the photovoltaic response. At an optimal gate voltage of $+2 \mathrm{~V}$, we obtain an open-circuit voltage of $V_{\text {oc }}=0.53 \mathrm{~V}$ and an efficiency of $1.9 \%$ under AM 1.51 -sun solar illumination. This work demonstrates that the field effect can be used to modulate and optimize the response of photovoltaic devices incorporating graphene.

KEYWORDS: Graphene, zinc phosphide, field effect solar cell, Schottky barrier, earth-abundant materials, photovoltaics
$T^{\mathrm{k}}$ he extraordinary properties of graphene, such as its high carrier mobility, Fermi-level tuning and its high optical transparency, make it an attractive candidate to improve the performance of optoelectronic and photovoltaic devices. ${ }^{1-3}$ These properties can be exploited for tackling some of the major challenges in solar energy. One challenge is to exploit Earth-abundant and low-cost synthesis materials with band gaps suitable for solar energy conversion. Besides common PV absorbers like $\mathrm{Si}, \mathrm{CdTe}$, and CIGS, there are other materials that have the potential for large scale solar implementation at lower costs, such as zinc phosphide $\left(\mathrm{Zn}_{3} \mathrm{P}_{2}\right)$, copper zinc tin sulfide (CZTS), cuprous oxide $\left(\mathrm{Cu}_{2} \mathrm{O}\right)$, and iron sulfide $\left(\mathrm{FeS}_{2}\right) .{ }^{4}$ However, the lack of doping processes necessary to form homojuntions and the absence of complementary emitter materials to form high quality $\mathrm{p}-\mathrm{n}$ heterojunction have limited the conversion efficiency of devices incorporating these materials. These limitations can be addressed using graphene, which has previously been used to form graphene-semiconductor junctions ${ }^{5}$ and solar cells with $\mathrm{CdS}$ and $\mathrm{CdSe} \mathrm{e}^{6,7}$ semiconductors as well as with $\mathrm{Si}^{5,8-11}$ demonstrating Schottky barrier behavior. ${ }^{5}$ Further advances on graphene-semiconductor junctions were demonstrated by building gate-controlled devices in order to modify the Schottky barrier height and the electrical transport across the junction. This design has been used to build a graphene-Si transistor (barristor) ${ }^{12}$ and a graphene-organic thin film junction transistors. ${ }^{9,13}$

Herein, we study the barrier tuning of a graphene- $-\mathrm{Zn}_{3} \mathrm{P}_{2}$ field-effect solar cell with a semitransparent top-gate electrode and demonstrate that this tuning can improve the photovoltaic efficiency of the cell. Field-effect solar cells were demonstrated recently by Regan et al. ${ }^{14}$ The principle of the field-effect solar cell is to use a transparent top gate to modulate the potential barrier and the electric field in a metal-semiconductor junction to separate photogenerated electron-hole pairs. The Fermilevel tuning of graphene is a key element to control the junction barrier between graphene and a semiconductor. As a semiconductor absorber we employ $\mathrm{Zn}_{3} \mathrm{P}_{2}$, a promising lowcost $\mathrm{p}$-type semiconductor with a high visible-light absorption coefficient $>10^{4} \mathrm{~cm}^{-1},{ }^{15-17}$ a suitable direct band gap of 1.5 $\mathrm{eV}^{16}$ and a minority electron diffusion length $>5 \mu \mathrm{m} .{ }^{18}$ The

Received: March 11, 2014

Revised: July 14, 2014

Published: July 24, 2014 


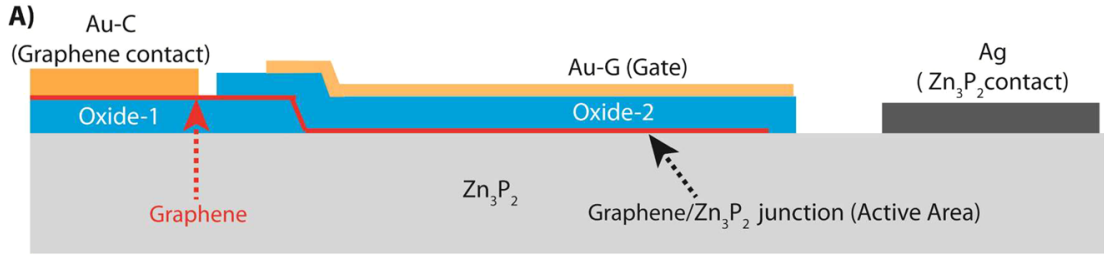

B)

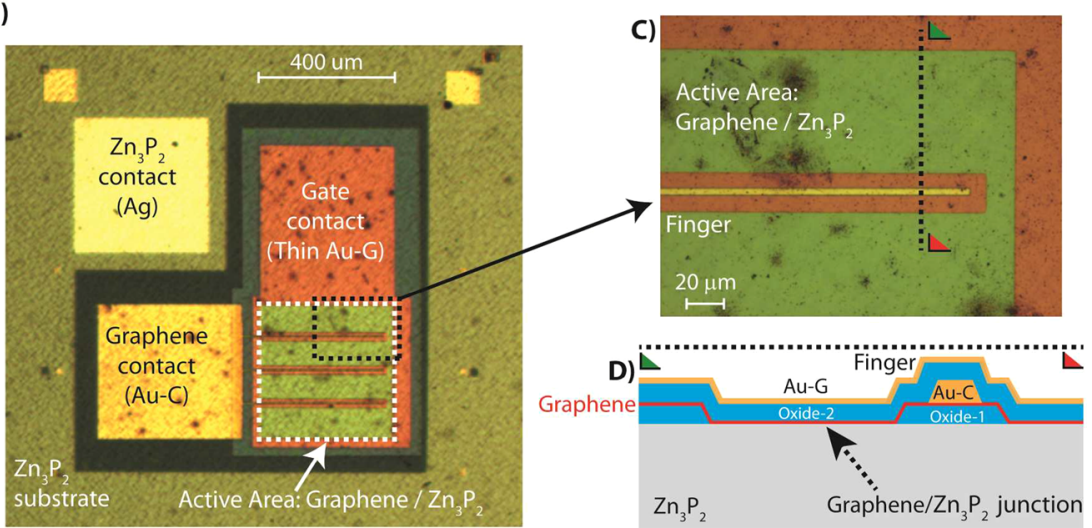

Figure 1. (A) Cross section schematics of the device showing a graphene sheet on top of $\mathrm{Zn}_{3} \mathrm{P}_{2}$ with a Au-C contact to the graphene isolated from the $\mathrm{Zn}_{3} \mathrm{P}_{2}$ by the Oxide-1 layer. The Oxide- 2 is the gate dielectric and a thin $\mathrm{Au}-\mathrm{G}$ layer the semitransparent top gate. Finally, a silver pad is used to contact $\mathrm{Zn}_{3} \mathrm{P}_{2}$. (B) Optical top-view image of the device showing the active area where the graphene- $\mathrm{Zn}_{3} \mathrm{P}_{2}$ junction is formed, the gate electrode, and the graphene, and the $\mathrm{Zn}_{3} \mathrm{P}_{2}$ contact pads. The finger structures on the active area are extensions of the graphene contact (Au-C). (C) Zoom-in of a section of the active area on one of the fingers made of Oxide- 1 and $\mathrm{Au}-\mathrm{C}$ layers. (D) Cross section across the dotted line in (C) showing the structure of the finger with the $\mathrm{Au}-\mathrm{C}$ contacting graphene and Oxide-1 as insulating layer.
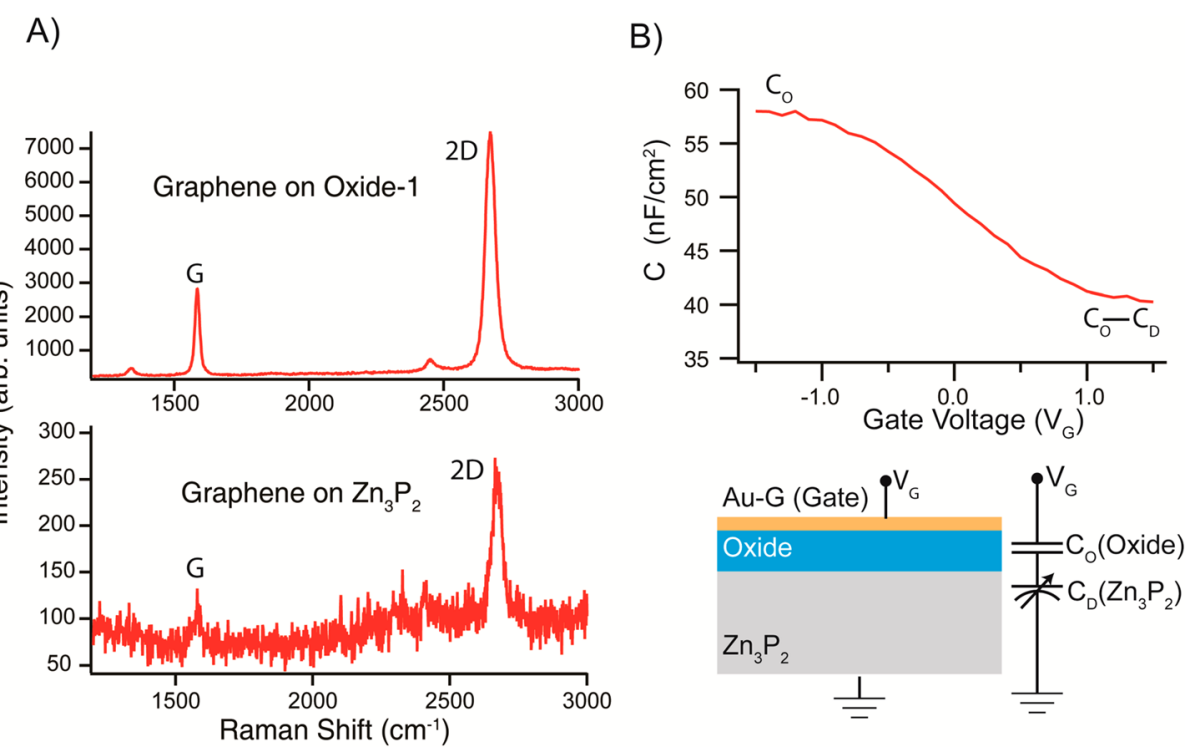

Figure 2. (A) Raman spectra of graphene on Oxide-1 and on $\mathrm{Zn}_{3} \mathrm{P}_{2}$ after transferring from $\mathrm{Cu}$ foil to the substrate. The spectra peaks show the presence of single layer graphene on the Oxide-1 and $\mathrm{Zn}_{3} \mathrm{P}_{2}$. (B) Gate capacitance versus gate voltage for a metal-oxide-semiconductor configuration ( $\mathrm{Au}$-oxide- $\mathrm{Zn}_{3} \mathrm{P}_{2}$ ) structure. The plot shows the capacitance reduction for positive $V_{\mathrm{G}}$ due to depletion of holes in $\mathrm{Zn}_{3} \mathrm{P}_{2}$. From this plot $\mathrm{a} \sim 76 \mathrm{~nm}$ depletion width and hole concentration of $\mathrm{p} \sim 6 \times 10^{16} \mathrm{~cm}^{-3}$ are estimated.

gate control allows us to improve the efficiency response of the field-effect graphene- $\mathrm{Zn}_{3} \mathrm{P}_{2}$ cell from 0.8 to $1.9 \%$ by controlling the junction barrier height, as well as turning off the cell to get an ohmic device. The device fabrication is based on chemical vapor deposited graphene and conventional microfabrication techniques. The electrical properties of the device are studied by current and capacitance measurements that show the control of the junction barrier height with the gate electrode. We discuss the role of the gate-modulated Fermi level and band bending within $\mathrm{Zn}_{3} \mathrm{P}_{2}$ and their relation to the
Schottky barrier height and the photovoltaic response of the device.

The structure of our device is shown in Figure 1A,B, consisting of a graphene monolayer on top of a $\mathrm{Zn}_{3} \mathrm{P}_{2}$ layer forming the device junction. On top of the graphene, there is a dielectric layer (Oxide-2) and a gate electrode made of a thin, semitransparent gold layer $(\mathrm{Au}-\mathrm{G})$. The graphene is contacted by a gold electrode $(\mathrm{Au}-\mathrm{C})$ insulated from the $\mathrm{Zn}_{3} \mathrm{P}_{2}$ by another oxide layer (Oxide-1). This $\mathrm{Zn}_{3} \mathrm{P}_{2}$ layer is $7 \mu \mathrm{m}$ thick and deposited on a $\sim 350 \mu \mathrm{m}$ Zn-doped GaAs(001) substrate. 

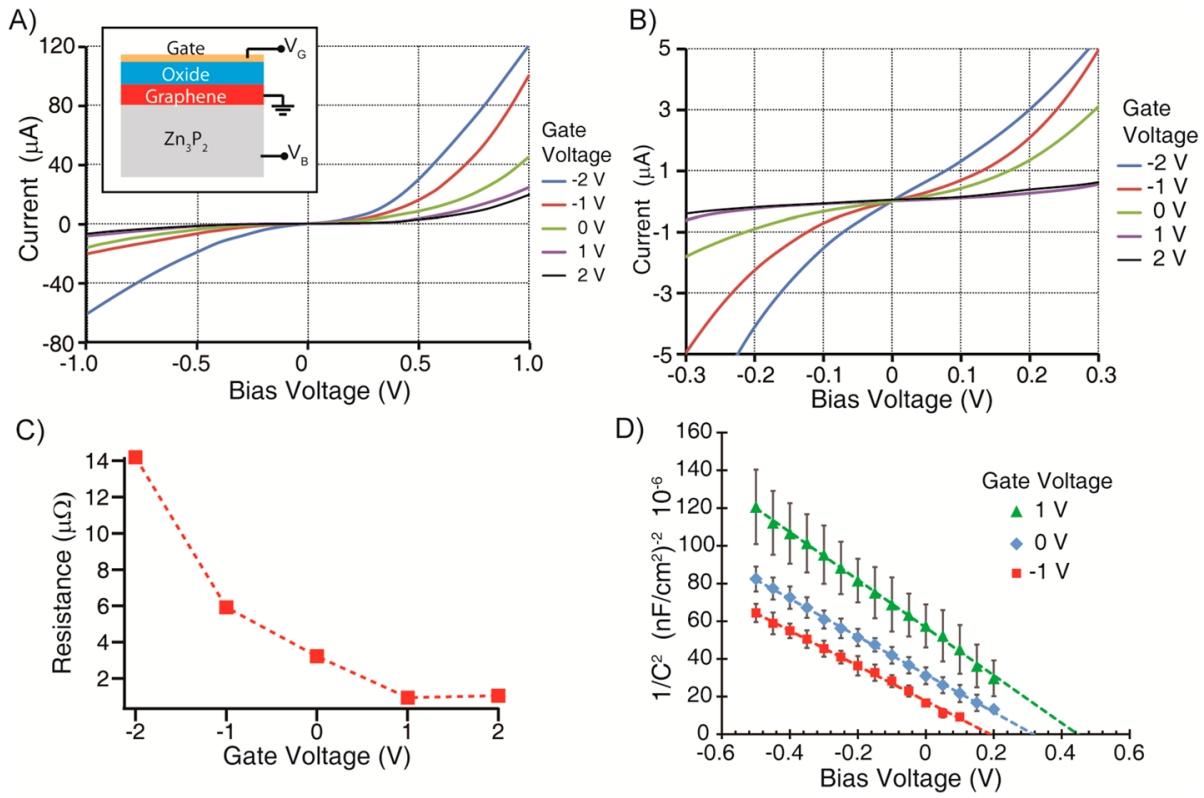

Figure 3. (A) $I\left(V_{\mathrm{B}}\right)$ dc characteristic of the device at different $V_{\mathrm{G}}$ showing a current suppression for positive $V_{\mathrm{G}}$. The inset shows the electrical measurement configuration. The curves show an asymmetric behavior with larger currents for positive $V_{\mathrm{B}}$. (B) $I\left(V_{\mathrm{B}}\right)$ curves at low voltages, showing an ohmic behavior for $V_{\mathrm{G}}=-2 \mathrm{~V}$ and a strong current suppression at positives $V_{\mathrm{G}}$. (C) Resistance $I / V_{\mathrm{B}}$ as a function of $V_{\mathrm{G}}$ at $V_{\mathrm{B}}=0$. (D) $C\left(V_{\mathrm{B}}\right.$ ) measurements at different $V_{\mathrm{G}}$. The values are averaged over a series of five measurements and the errors bars correspond to the standard deviation (further details in Supporting Information). The plot shows the increase in potential barrier (reduced capacitance) for reverse biasing and the increase of the built-in potential (extrapolation to $1 / C^{2}=0$ ) for positive $V_{\mathrm{G}}$. All measurements are taken at room temperature in ambient conditions.

The $\mathrm{Zn}_{3} \mathrm{P}_{2}$ film was grown by molecular-beam epitaxy (MBE) at $200{ }^{\circ} \mathrm{C}$ using a beam equivalent pressure of $1 \times 10^{-6}$ Torr, the details of which have been described previously. ${ }^{19}$ The graphene sheet was grown by chemical vapor deposition (CVD) on a $\mathrm{Cu}$ foil and then transferred onto the $\mathrm{Zn}_{3} \mathrm{P}_{2}$. The device fabrication is shown in detail in the Supporting Information section A. Figure 1B shows an optical top-view of the device with the graphene, gate, and $\mathrm{Zn}_{3} \mathrm{P}_{2}$ contacts, as well as the active area showing finger electrodes to facilitate the electrical current collection from graphene. Figure $1 \mathrm{C}$ shows a zoom-in of one of the fingers in the active area. Figure 1D shows a schematic cross section of the structure in Figure 1C with the graphene- $-\mathrm{Zn}_{3} \mathrm{P}_{2}$ junction under the gate dielectric (Oxide-2) and gate electrode (Au-G), as well as the graphene contact $(\mathrm{Au}-\mathrm{C})$ isolated from the $\mathrm{Zn}_{3} \mathrm{P}_{2}$ by the Oxide-1 layer.

Raman spectroscopy was used to characterize the graphene transferred onto the $\mathrm{Zn}_{3} \mathrm{P}_{2}$. Figure $2 \mathrm{~A}$ shows the Raman spectra (633 nm laser) taken on $\mathrm{Zn}_{3} \mathrm{P}_{2}$ (on the Active Area) and on the Oxide-1 layer after graphene transfer. The spectrum on Oxide-1 shows a single $2 \mathrm{D}$ peak larger than the $\mathrm{G}$ peak, a clear sign of single layer graphene. ${ }^{5,20}$ The spectrum on $\mathrm{Zn}_{3} \mathrm{P}_{2}$ has the same characteristics but with lower signal intensity. The data indicates that we have single layer graphene on our substrate. The hole carrier concentration and depletion width of the $\mathrm{Zn}_{3} \mathrm{P}_{2}$ were evaluated by gate capacitance measurements in a device with a metal-oxide-semiconductor configuration. ${ }^{21}$ The measurements, schematic and circuit diagram of the capacitance versus gate voltage, $C\left(V_{\mathrm{G}}\right)$, on $\mathrm{Zn}_{3} \mathrm{P}_{2}$ are shown in Figure 2B. The behavior of $C\left(V_{\mathrm{G}}\right)$ shows that the $\mathrm{Zn}_{3} \mathrm{P}_{2}$ depletion width and band bending can be modulated with $V_{\mathrm{G}}$. At negative $V_{\mathrm{G}}$, an accumulation of holes occurs at the semiconductor-oxide interface and the capacitance of the oxide layer $\left(C_{\mathrm{O}}\right)$ is the main contributor. However, for positive $V_{\mathrm{G}}$ a depletion layer is induced in the $\mathrm{Zn}_{3} \mathrm{P}_{2}$ at the interface with the oxide layer, adding a capacitance, $C_{D}$, in series with $C_{O}$ and reducing the total capacitance. From these values, we calculate a maximal depletion width of $\sim 76 \mathrm{~nm}$, corresponding to a hole concentration of $6 \times 10^{16} \mathrm{~cm}^{-3}$ (calculations shown in Supporting Information section C). This is in good agreement with Bosco et al., who report a carrier concentration of $\sim 1 \times$ $10^{17} \mathrm{~cm}^{-3}$ for $\mathrm{Zn}_{3} \mathrm{P}_{2}$ epilayers prepared with the same process. $^{19,22}$

The current versus bias voltage transport curves across the graphene $-\mathrm{Zn}_{3} \mathrm{P}_{2}$ junction, $I\left(V_{\mathrm{B}}\right)$, are shown in Figure 3A,B. The measurements are taken in dc mode at room temperature and ambient conditions with the graphene electrode grounded $(\mathrm{Au}-\mathrm{C})$, the $V_{\mathrm{B}}$ is applied to the $\mathrm{Zn}_{3} \mathrm{P}_{2}$ via the $\mathrm{Ag}$ electrode and the $V_{\mathrm{G}}$ is applied via the $\mathrm{Au}-\mathrm{G}$ electrode. The measurements show that the current across the junction depends on $V_{\mathrm{G}}$ and that the barrier at the junction can be modulated. Figure 3B shows the $I\left(V_{\mathrm{B}}\right)$ curves at a smaller range of $V_{\mathrm{B}}>|0.3| \mathrm{V}$ showing a higher conductivity at negative gate voltages and a reduced conductivity at positive gate voltages. The resistance determined from the $I\left(V_{\mathrm{B}}\right)$ curved at $V_{\mathrm{B}}=0$ is plotted as a function of the gate voltage in Figure 3C. The $I\left(V_{\mathrm{B}}\right)$ curves also show an asymmetry, especially at $V_{\mathrm{G}}=-1 \mathrm{~V}$ with higher current at positive $\mathrm{Zn}_{3} \mathrm{P}_{2}$ bias. This can be attributed to a Schottky diode behavior with graphene as the metal and $\mathrm{Zn}_{3} \mathrm{P}_{2}$ as the p-type semiconductor. Schottky behavior in graphene-semiconductor junctions has been previously reported for different semiconductors. ${ }^{5}$ As expected for a Schottky diode, the current increases when the $\mathrm{p}$ semiconductor is positively biased. To further study the gate effect on the Schottky barrier, we performed a series of capacitance measurements as a function of the bias voltage $C\left(V_{\mathrm{B}}\right)$. On the basis of the expression $1 / C^{2}=2\left(V_{\mathrm{B}}-V_{\mathrm{bi}}\right) /$ $\left(q \varepsilon_{\mathrm{sc}} N_{\mathrm{A}}\right){ }^{21}$ the extrapolated value of $1 / C^{2}$ to the abscissa corresponds to the built-in potential $\left(V_{\mathrm{bi}}\right)$ and from the slope the carrier density is extracted. The dielectric constant of $\mathrm{Zn}_{3} \mathrm{P}_{2}$ is $\varepsilon_{\mathrm{sc}} \sim 11 \varepsilon_{\mathrm{o}}$ and $N_{\mathrm{A}}$ is the acceptor concentration, which is 
A)

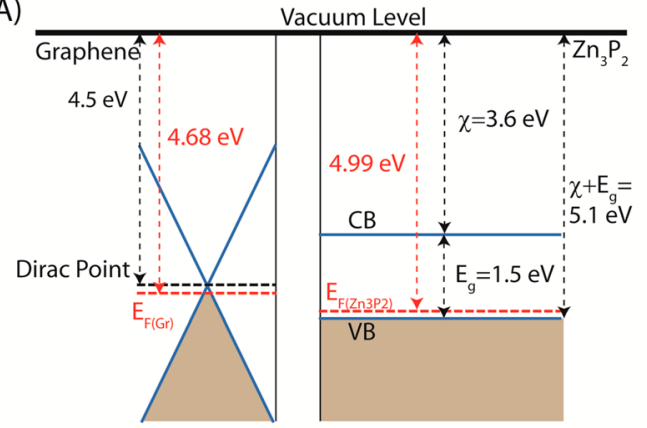

C)

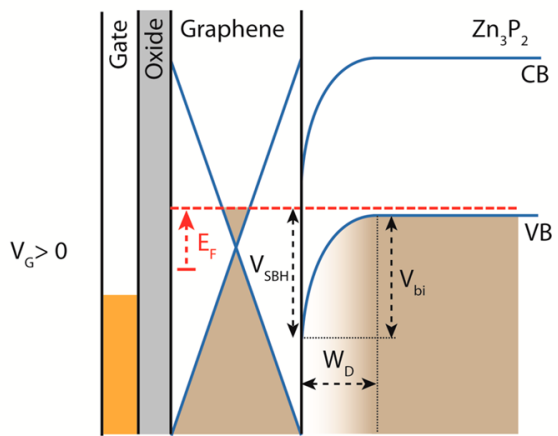

B)

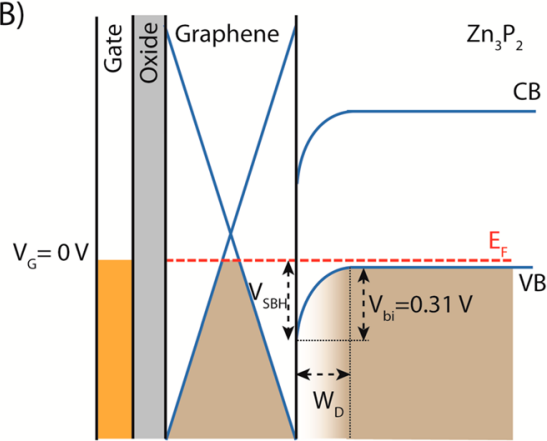

D)

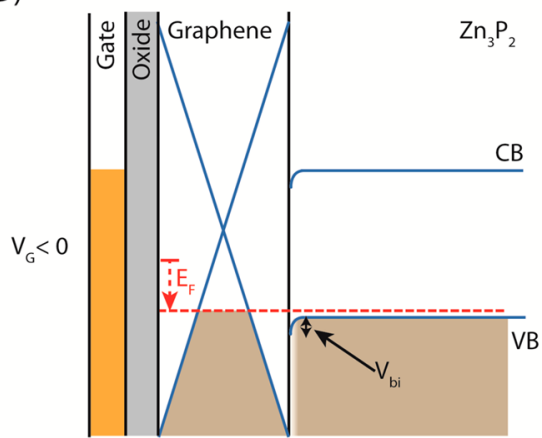

Figure 4. (A) Band structure of graphene and $\mathrm{Zn}_{3} \mathrm{P}_{2}$ before equilibrium. The graphene Dirac-point and $\mathrm{Zn}_{3} \mathrm{P}_{2}$ valence and conduction bands are determined by material properties. Fermi levels of graphene and $\mathrm{Zn}_{3} \mathrm{P}_{2}$ are calculated from measurements. (B) Band bending after the junction reaches equilibrium, inducing a barrier to the holes emitted into graphene. On the basis of the $C\left(V_{\mathrm{B}}\right)$ measurements, the built-in potential across the junction at $V_{\mathrm{G}}=0$ is $V_{\mathrm{bi}}=0.31 \pm 0.04 \mathrm{~V}$. (C) When $V_{\mathrm{G}}$ increases to positive values, it raises the Fermi level in graphene inducing a higher Schottky barrier and depletion width in the $\mathrm{Zn}_{3} \mathrm{P}_{2}$. (D) For negative $V_{\mathrm{G}}$, the band bending and barrier height are reduced, easing the transport across the junction.

approximately equal to the hole concentration. $V_{\mathrm{bi}}$ is equal to the difference in Fermi energies between graphene and $\mathrm{Zn}_{3} \mathrm{P}_{2}$. Figure $3 \mathrm{D}$ shows $1 / \mathrm{C}^{2}$ as a function of $V_{\mathrm{B}}$ on the graphene$\mathrm{Zn}_{3} \mathrm{P}_{2}$ junction averaging from multiple measurements (details on the multiple measurements are reported in the Supporting Information section $\mathrm{B}$ ). As $V_{\mathrm{B}}$ goes to negative values, the capacitance decreases, pointing to an increase in the depletion width in the $\mathrm{Zn}_{3} \mathrm{P}_{2}$ and hence a higher potential barrier, which is in agreement with the $I\left(V_{\mathrm{B}}\right)$ data in Figure 3. From this measurement, we extract a hole-carrier density of $N_{\mathrm{A}} \sim p \sim$ $9.88 \times 10^{16} \mathrm{~cm}^{-3}$ and a built-in potential $V_{\mathrm{bi}} \sim 0.31 \pm 0.04 \mathrm{~V}$ at $V_{\mathrm{G}}=0 \mathrm{~V}$ (see Supporting Information section $\mathrm{C}$ for details on calculations). The carrier density extracted from the $C\left(V_{\mathrm{B}}\right)$ is higher but near in order of magnitude to the value extracted from $C\left(V_{\mathrm{G}}\right)$ in Figure $2 \mathrm{~B}$ of $6 \times 10^{16} \mathrm{~cm}^{-3}$. As expected, $V_{\mathrm{bi}}$ varies with $V_{\mathrm{G}}$, increasing to $0.44 \pm 0.06 \mathrm{~V}$ at $V_{\mathrm{G}}=1 \mathrm{~V}$ and diminishing to $0.18 \pm 0.02 \mathrm{~V}$ at $V_{\mathrm{G}}=-1 \mathrm{~V}$. As $V_{\mathrm{G}}$ goes to positive values, the junction barrier increases and the current is reduced. The joint analysis of $I\left(V_{\mathrm{B}}\right)$ and $C\left(V_{\mathrm{B}}\right)$ indicates that the presented device works as a semiconductor("p")-metal Schottky junction modulated by a gate voltage.

The behavior of the device can be analyzed in terms of the band diagrams for graphene and $\mathrm{Zn}_{3} \mathrm{P}_{2}$. Figure $4 \mathrm{~A}$ shows the bands before reaching equilibrium with respect to the vacuum level. The position of the graphene Dirac point with respect to the vacuum level $(4.5 \mathrm{eV}),{ }^{23}$ and the positions of the conduction (electron affinity $\chi=3.6 \mathrm{eV})^{24}$ and valence bands $\left(\chi+E_{\mathrm{g}}=5.1 \mathrm{eV}\right)$ of $\mathrm{Zn}_{3} \mathrm{P}_{2}$ can be considered independent of doping levels or gating. ${ }^{22,25}$ When the materials come together, bending of the $\mathrm{Zn}_{3} \mathrm{P}_{2}$ conduction and valence bands is dependent on Fermi energies which further depend on the doping and gating levels. We can infer the position of the bulk Fermi level $\left(E_{\mathrm{F}}\right)$ of $\mathrm{Zn}_{3} \mathrm{P}_{2}$ from the doping concentration calculated from Figure $2 \mathrm{~B}$ of $6 \times 10^{16} \mathrm{~cm}^{-3}$, giving a difference between $E_{\mathrm{F}}$ and valence band of $0.11 \mathrm{eV}$, and hence $4.99 \mathrm{eV}$ below the vacuum level. From the $E_{\mathrm{F}}$ of $\mathrm{Zn}_{3} \mathrm{P}_{2}$ and band bending $\left(V_{\mathrm{bi}}\right)$ we can also infer the graphene $E_{\mathrm{F}}$. From Figure $3 \mathrm{D}$ we obtained a $V_{\mathrm{bi}} \sim 0.31$ at $0 V_{\mathrm{G}}$, inferring that the $E_{\mathrm{F}}$ of graphene is located $0.31 \mathrm{eV}$ above the $\mathrm{E}_{\mathrm{F}}$ of $\mathrm{Zn}_{3} \mathrm{P}_{2}$ and $4.68 \mathrm{eV}$ below the vacuum level. Figure $4 \mathrm{~B}$ shows the actual induced valence and conduction band bending after equilibrium with the depletion layer $\left(W_{\mathrm{D}}\right)$ induced in the $\mathrm{Zn}_{3} \mathrm{P}_{2}$. On the basis of this picture, we can understand the behavior of the junction when $V_{\mathrm{G}}$ is increased to positive values as in Figure 4 C. As $V_{\mathrm{G}}$ increases, the $E_{\mathrm{F}}$ of graphene goes higher, thus increasing the band bending and depletion layer. Hence, the holes have to cross a higher barrier and the current of the device is decreased. This band bending picture corresponds to a Schottky barrier configuration, explaining the asymmetry of higher current levels when the $\mathrm{Zn}_{3} \mathrm{P}_{2}$ is positively biased. In the opposite way, pushing $V_{\mathrm{G}}$ toward negative values would decrease the potential barrier as shown in Figure 4D. When $V_{\mathrm{G}}$ is increased from 0 to $1 \mathrm{~V}$, the change in built-in potential $\Delta V_{\mathrm{bi}}$ is $V_{\mathrm{bi}}\left(V_{\mathrm{G}}=1\right)-$ $\mathrm{V}_{\mathrm{bi}}\left(V_{\mathrm{G}}=0\right)=0.44-0.31=0.13 \pm 0.07 \mathrm{~V}$. This value is close (within the error tolerance) to the estimated change in Fermi energy in graphene $\Delta E_{\mathrm{F}} \sim 0.11 \mathrm{eV}$ when $V_{\mathrm{G}}=1 \mathrm{~V}$ is applied across the dielectric layer, Oxide-2, that has a capacitance of $C$ $\sim 107 \mathrm{nF} / \mathrm{cm}^{2}$. The details on the estimated induced change in Fermi energy in graphene and built-in potential are described in the Supporting Information section C. Even though the model presented in Figure 4 ignores surface trap states at junction, it 
provides an adequate picture of the device in close agreement with the measurements obtained.

We measured the photovoltaic response of the device under simulated AM-1.5 1-sun solar illumination. The photovoltaic current, $I(V)$, and power, $P(V)$, are shown in Figure 5. The
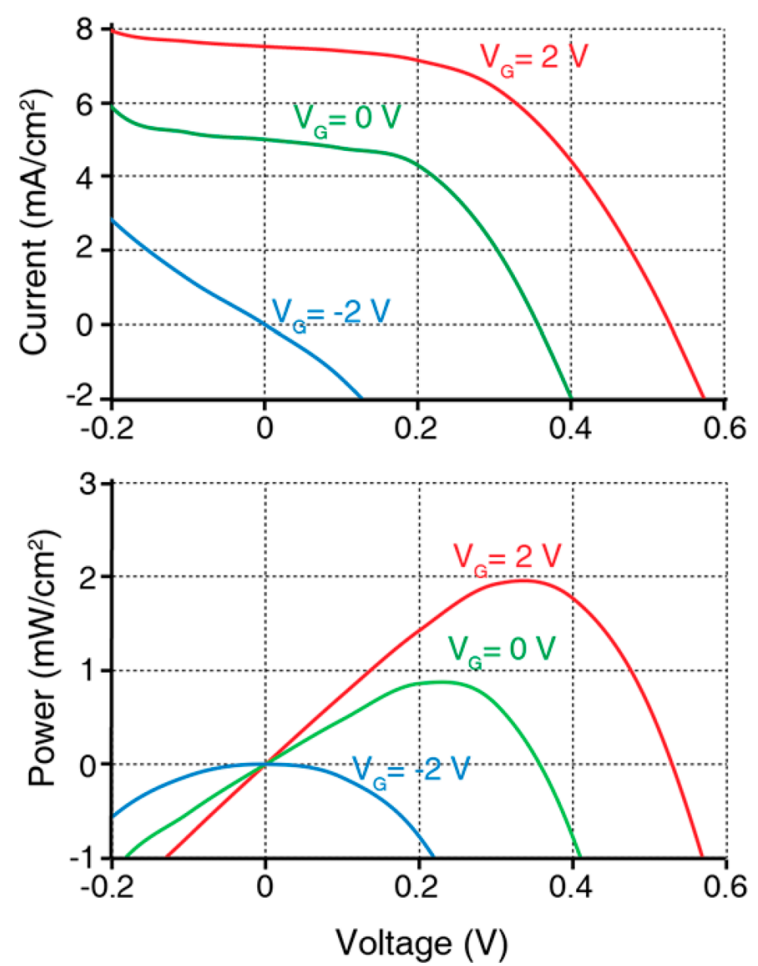

Figure 5. Photovoltaic response of the cell under AM 1.5 illumination showing the photocurrent (top) and power (bottom) as a function of $\mathrm{V}_{\mathrm{B}}$ for different gate voltages. At $V_{\mathrm{G}}=-2 \mathrm{~V}$, the junction has an ohmic behavior and there is no short-circuit current. At $V_{\mathrm{G}}=0$ the device behaves as a Schottky solar cell due to the barrier formed at the graphene $-\mathrm{Zn}_{3} \mathrm{P}_{2}$ interface with a power output of $0.88 \mathrm{~mW} / \mathrm{cm}^{2}$ at $V_{\mathrm{B}}$ $=0.22 \mathrm{~V}$ and with a $V_{\mathrm{oc}}$ of $0.35 \mathrm{~V}$. Applying a $V_{\mathrm{G}}=2 \mathrm{~V}$, the barrier is increased giving an enhanced performance of the cell. The power increases to $1.9 \mathrm{~mW} / \mathrm{cm}^{2}$ and $V_{\text {oc }}$ to $0.53 \mathrm{~V}$.

response at $0 V_{\mathrm{G}}$ gives a maximum power output of $0.88 \mathrm{~mW} /$ $\mathrm{cm}^{2}$ at $V_{\mathrm{B}}=0.22 \mathrm{~V}$, an open-circuit voltage of $V_{\mathrm{oc}}=0.35 \mathrm{~V}$, and short-circuit current of $I_{\mathrm{sc}}=5.18 \mathrm{~mA} / \mathrm{cm}^{2}$. The efficiency achieved is $\eta=0.88 \%$ with a fill factor of $\mathrm{FF}=0.48$. We are able to improve the performance of the device by increasing $V_{\mathrm{G}}$ and thus increasing the Schottky barrier. At $V_{\mathrm{G}}=2 \mathrm{~V}$, we obtain a higher output power of $1.9 \mathrm{~mW} / \mathrm{cm}^{2}$ at $V_{\mathrm{B}}=0.33 \mathrm{~V}$ with $V_{\text {oc }}=$ $0.53 \mathrm{~V}, I_{\mathrm{sc}}=7.5 \mathrm{~mA} / \mathrm{cm}^{2}, \eta=1.9 \%$ and $\mathrm{FF}=0.53$. Similarly, the cell can be turned off by applying a negative gate voltage. At $V_{\mathrm{G}}$ $=-2 \mathrm{~V}$, the potential barrier across the junction is suppressed, as expected from Figures 3 and 4, giving a negative power output similar to a resistor. The leakage current through the gate at $V_{\mathrm{G}}=2 \mathrm{~V}$ was $I_{\mathrm{G}}=12.6 \mu \mathrm{A} / \mathrm{cm}^{2}$. This represents a gate power of $25.2 \mu \mathrm{W} / \mathrm{cm}^{2}$ and only $1.3 \%$ of the power output of the cell at $V_{\mathrm{G}}=2 \mathrm{~V}$.

These results demonstrate that the tuning of the graphenesemiconductor junction allows boosting the performance of the solar cell by improving parameters like $V_{\text {oc }}$. The $1.9 \%$ efficiency achieved in this work is comparable with thin-film $\mathrm{Zn}_{3} \mathrm{P}_{2}$ devices based on $\mathrm{p}-\mathrm{n}$ junction solar cells. ${ }^{26-28}$ Even though our efficiency falls short from the highest reported $\mathrm{Zn}_{3} \mathrm{P}_{2}$ cell efficiency of $5.96 \%\left(\mathrm{Mg}-\mathrm{Zn}_{3} \mathrm{P}_{2}\right.$ Schottky cell $),{ }^{29,30}$ the performance of our graphene- $\mathrm{Zn}_{3} \mathrm{P}_{2}$ has significant room for improvement. Using a thicker $\mathrm{Zn}_{3} \mathrm{P}_{2}$ layer to improve light absorption, as well as a transparent conductive oxide as a top gate would increase the power efficiency of the device. Also, doping the graphene layer has shown to enhance the performance of graphene-silicon solar cells. ${ }^{11} \mathrm{We}$ can also expect that further increasing $V_{\mathrm{G}}$ will increase the barrier height and further enhance the performance of the cell.

In conclusion, in this work we demonstrate a graphene$\mathrm{Zn}_{3} \mathrm{P}_{2}$ junction modulated by a gate electrode that controls the barrier height and the conductivity as demonstrated by $C\left(V_{\mathrm{B}}\right)$ and $I\left(V_{\mathrm{B}}\right)$ measurements. The gate voltage controls the Fermi level of graphene and the band bending in the $\mathrm{Zn}_{3} \mathrm{P}_{2}$. The photovoltaic response also demonstrates the behavior of the device as a field-effect solar cell. The properties of the fieldeffect cell are controlled by the gate electrode, offering the possibility to improve the performance of the cell beyond the intrinsic properties of the materials forming the junction. Further performance enhancements in these devices could be obtained by optimizing different elements like the gate dielectric, gate electrode, and graphene doping. Because graphene has also showed Schottky junctions with other materials besides $\mathrm{Zn}_{3} \mathrm{P}_{2}$, we believe this can open a route for photovoltaics using other earth abundant materials with graphene field-effect solar cells.

\section{ASSOCIATED CONTENT}

\section{S Supporting Information}

Information on the sample fabrication process flow; series of capacitance measurements; calculations on carrier concentration, change in graphene Fermi level and built-in potential; and photovoltaic measurements. This material is available free of charge via the Internet at http://pubs.acs.org.

\section{AUTHOR INFORMATION}

\section{Corresponding Authors}

*E-mail: (A.Z.) azettl@berkeley.edu.

*E-mail: (O.V.-M.) oscar.vazquezmena@gmail.com.

\section{Author Contributions}

O.V.M., O.E., M.C., and A.Z. conceived the experiment and devices; J.P.B. and H.A.A. produced the zinc-phosphide films; O.V.M, H.I.R, and A.F. contributed to device fabrication; M.T. and A.J. produced high-quality dielectric layers; O.V.M. performed the measurements and data analysis; O.V.M. wrote the manuscript; all authors discussed the results and commented on the manuscript.

\section{Notes}

The authors declare no competing financial interest.

\section{ACKNOWLEDGMENTS}

This research was supported in part by the Office of Energy Research, Materials Sciences and Engineering Division of the U.S. Department of Energy under Contract No. DE-AC0205CH11231, which provided for the design of the experiment and Raman spectroscopy characterization; the National Science Foundation within the Center of Integrated Nanomechanical Systems, under Grant EEC-0832819, which provided for photovoltaic response characterization; and by the Office of Naval Research (MURI) under Grant N00014-09-1066, which provided for graphene growth and device assembly. O.V.M. acknowledges the support of the Swiss National Science Foundation through the fellowship for Advanced Researchers 
PA00P2 145394. J.P.B. and H.A.A. acknowledge the support of the DOW Chemical Company. The authors also would like to thank to C. Ojeda-Aristizabal, J. Velasco, W. Regan, and Professor F. Wang for fruitful discussions.

\section{REFERENCES}

(1) Novoselov, K. S.; Geim, A. K.; Morozov, S. V.; Jiang, D.; Zhang, Y.; Dubonos, S. V.; Grigorieva, I. V.; Firsov, A. A. Science 2004, 306, 666-669.

(2) Geim, A. K. Science 2009, 324, 1530-1534.

(3) Britnell, L.; Gorbachev, R. V.; Jalil, R.; Belle, B. D.; Schedin, F.; Mishchenko, A.; Georgiou, T.; Katsnelson, M. I.; Eaves, L.; Morozov, S. V.; Peres, N. M. R.; Leist, J.; Geim, A. K.; Novoselov, K. S.; Ponomarenko, L. A. Science 2012, 335, 947-950.

(4) Wadia, C.; Alivisatos, A. P.; Kammen, D. M. Environ. Sci. Technol. 2009, 43, 2072-2077.

(5) Tongay, S.; Lemaitre, M.; Miao, X.; Gila, B.; Appleton, B. R.; Hebard, A. F. Phys. Rev. X 2012, 2, 011002.

(6) Ye, Y.; Dai, Y.; Dai, L.; Shi, Z.; Liu, N.; Wang, F.; Fu, L.; Peng, R.; Wen, X.; Chen, Z.; Liu, Z.; Qin, G. ACS Appl. Mater. Interfaces 2010, 2, 3406-3410.

(7) Zhang, L.; Fan, L.; Li, Z.; Shi, E.; Li, X.; Li, H.; Ji, C.; Jia, Y.; Wei,

J.; Wang, K.; Zhu, H.; Wu, D.; Cao, A. Nano Res. 2011, 4, 891-900.

(8) Chen, C.-C.; Aykol, M.; Chang, C.-C.; Levi, A. F. J.; Cronin, S. B. Nano Lett. 2011, 11, 1863-1867.

(9) Lemaitre, M. G.; Donoghue, E. P.; McCarthy, M. A.; Liu, B.; Tongay, S.; Gila, B.; Kumar, P.; Singh, R. K.; Appleton, B. R.; Rinzler, A. G. ACS Nano 2012, 6, 9095-9102.

(10) Li, X.; Zhu, H.; Wang, K.; Cao, A.; Wei, J.; Li, C.; Jia, Y.; Li, Z.; Li, X.; Wu, D. Adv. Mater. 2010, 22, 2743-2748.

(11) Miao, X.; Tongay, S.; Petterson, M. K.; Berke, K.; Rinzler, A. G.; Appleton, B. R; Hebard, A. F. Nano Lett. 2012, 12, 2745-2750.

(12) Yang, H.; Heo, J.; Park, S.; Song, H. J.; Seo, D. H.; Byun, K.-E.; Kim, P.; Yoo, I.; Chung, H.-J.; Kim, K. Science 2012, 336, 1140-1143.

(13) Ojeda-Aristizabal, C.; Bao, W.; Fuhrer, M. S. Phys. Rev. B 2013, 88,035435 .

(14) Regan, W.; Byrnes, S.; Gannett, W.; Ergen, O.; Vazquez-Mena, O.; Wang, F.; Zettl, A. Nano Lett. 2012, 12, 4300-4304.

(15) Fagen, E. A. J. Appl. Phys. 1979, 50, 6505-6515.

(16) Kimball, G. M.; Mueller, A. M.; Lewis, N. S.; Atwater, H. A. Appl. Phys. Lett. 2009, 95, 112103.

(17) Pawlikowski, J. M. Phys. Rev. B 1982, 26, 4711-4713.

(18) Wyeth, N. C.; Catalano, A. J. Appl. Phys. 1979, 50, 1403-1407.

(19) Bosco, J. P.; Kimball, G. M.; Lewis, N. S.; Atwater, H. A. J. Cryst. Growth 2013, 363, 205-210.

(20) Ferrari, A. C.; Meyer, J. C.; Scardaci, V.; Casiraghi, C.; Lazzeri, M.; Mauri, F.; Piscanec, S.; Jiang, D.; Novoselov, K. S.; Roth, S.; Geim, A. K. Phys. Rev. Lett. 2006, 97, 187401.

(21) Sze, S. M. Semiconductor Devices, Physics and Technology, 2nd ed.; Wiley: New York, 2002.

(22) Bosco, J. P.; Scanlon, D. O.; Watson, G. W.; Lewis, N. S.; Atwater, H. A. J. Appl. Phys. 2013, 113, 203705.

(23) Xu, K.; Zeng, C.; Zhang, Q.; Yan, R.; Ye, P.; Wang, K.; Seabaugh, A. C.; Xing, H. G.; Suehle, J. S.; Richter, C. A.; Gundlach, D. J.; Nguyen, N. V. Nano Lett. 2012, 13, 131-136.

(24) Nelson, A. J.; Kazmerski, L. L.; Engelhardt, M.; Hochst, H. J. Appl. Phys. 1990, 67, 1393-1396.

(25) Bosco, J. P.; Demers, S. B.; Kimball, G. M.; Lewis, N. S.; Atwater, H. A. J. Appl. Phys. 2012, 112, 093703.

(26) Nayar, P. S.; Catalano, A. Appl. Phys. Lett. 1981, 39, 105-107.

(27) Suda, T.; Kuroyanagi, A.; Kurita, S. In Technical Digest, International PVSEC-1, 1984 ed.; IEEE: Kobe, Japan, 1984; p 381.

(28) Nayar, P. S. J. Appl. Phys. 1982, 53, 1069-1075.

(29) Bhushan, M.; Catalano, A. Appl. Phys. Lett. 1981, 38, 39-41.

(30) Bhushan, M. Appl. Phys. Lett. 1982, 40, 51-53. 